\title{
Commentary
}

\section{Why Do We Believe Humans Matter More than Other Animals?}

\author{
Scott Hill \\ University of Colorado Boulder, Hellems 169 UCB 232, Boulder, \\ CO 80309-0232, USA \\ hillscottandrew@gmail.com \\ Michael Bertrand \\ The Ohio State University, 35o University Hall, 230 N Oval Mall, \\ Columbus, $\mathrm{OH} 43210$, USA \\ bertrand.34@osu.edu
}

\begin{abstract}
Some recent psychological studies suggest that the belief that humans matter more than other animals can be strengthened by cognitive dissonance. Jaquet (forthcoming) argues that some of these studies also show that the relevant belief is primarily caused by cognitive dissonance and is therefore subject to a debunking argument. We offer an alternative hypothesis according to which we are already speciesist but cognitive dissonance merely enhances our speciesism. We argue that our hypothesis explains the results of the studies at least as well as Jaquet's. We then respond to a series of objections. Along the way, we highlight various respects in which further studies are needed to decide between Jaquet's hypothesis and ours.
\end{abstract}

\section{Keywords}

Jaquet F. - empirical psychology - racism - speciesism 
Most of us believe that humans matter much more than other animals. What is the source of this belief? In a series of experiments conducted by Jaquet and Cova (Jaquet, forthcoming, 8), respondents were asked to rate their agreement with the following statements on a scale from $(1=$ strongly disagree $)$ to $(6$ = strongly agree $)$ :

- We should always elevate the interests of humans over the interests of animals.

- When human interests conflict with animal interests, human interests should be given priority.

- Animals shouldn't be granted the same rights as humans with comparable mental capacities.

Meat-eating participants were placed in two groups. One was a manipulation group in which prior to rating, participants read a short vignette offering ethical reasons to avoid eating meat. The other was a control group in which participants read a vignette offering only non-ethical reasons to avoid meat. Members of the control group tended to rate agreement with the relevant statements between 3.6 and 3.8. Members of the manipulated group tended to rate agreement between 3.8 and 4.2. There were also vegetarian participants. They tended to rate agreement with the relevant statements around 2 indicating that they "rather disagree" with the statements. Now consider two hypotheses:

1. H1: Meat-eating causes cognitive dissonance which increases speciesist belief.

2. H2: Meat-eating causes cognitive dissonance which is the primary cause of speciesist belief.

H1 receives support from the experiments conducted by Jaquet and Cova (Jaquet, forthcoming, 9). When confronted with a vignette highlighting moral reasons to abstain from meat, non-vegetarian participants agreed with speciesist statements more strongly than when not so confronted. The hypothesis that meat eating enhances speciesist belief by way of cognitive dissonance explains this result.

Jaquet argues that the experiments support $\mathrm{H} 2$ as well:

What we did via the manipulation wasn't to create dissonance in our participants by confronting them to the meat paradox; we merely increased a dissonance that was already there by rendering the paradox more salient. But then, their dissonance probably had an effect on their speciesist beliefs too, since we know (from the experiment) that cognitive dissonance increases speciesist beliefs (forthcoming, 12). 
The thought is this: We know that cognitive dissonance increases speciesist belief from the relevant studies. Furthermore, we know that meat eaters in both groups experience cognitive dissonance since their behavior does not match some of their beliefs about how animals should be treated. What this suggests is that cognitive dissonance is already at work generating speciesist beliefs even before the experiment makes the dissonance more salient. So all meat eating participants start with a base level of cognitive dissonance prior to the studies. And that dissonance is just made more salient for participants given the vignette contain moral reasons to avoid meat. Thus, the results of the experiments are compatible with $\mathrm{H}_{2}$ and, Jaquet suggests, provide support for $\mathrm{H}_{2}$ (forthcoming, 12).

Another consideration Jaquet makes in favor of $\mathrm{H}_{2}$ is that there is a significant contrast in reports of speciesist beliefs between meat-eating participants (whatever vignette they were given) and the beliefs of vegetarian participants. As Jaquet puts it:

Besides the subjects mentioned so far, 81 vegetarian participants took part in our experiments, and their scores on the speciesism scale were extremely low as compared to those of meat-eaters-their mean result corresponded to the answer "rather disagree" (with the speciesist statements). This suggests not only that our meat-eater participants experienced cognitive dissonance, but also that their speciesist beliefs were mainly caused by dissonance-indeed, the difference between our control subjects and our vegetarian participants is easily explained by the former's dissonance. All in all, it looks very much like meat-eaters form the speciesist belief because they experience dissonance (forthcoming, 13).

The argument is this: The non-meat eaters indicate disagreement with speciesist statements. The meat-eaters indicate agreement. The non-meat eaters do not experience cognitive dissonance. The meat eaters do. We know from the relevant studies that cognitive dissonance is sufficient to generate speciesist belief. There is no other obvious candidate for what generates speciesist belief. So we should conclude that cognitive dissonance is the primary cause of speciesist belief. And in this way the experiments support $\mathrm{H}_{2}{ }^{1}$

1 Jaquet says that "countless common-sense observations suggest that people do not hold speciesist beliefs in specific areas in which their behavior doesn't harm animals. They are for instance vehemently opposed to cockfights, bullfighting, whaling, hunting safaris, and dog-meat festivals, unless they partake in these activities" (forthcoming, 12). I think this is mistaken. Consider dogs. The standard view is that dogs matter less than humans. But we do not eat dogs. The hypothesis that cognitive dissonance merely enhances, but does not 
Imagine a study is conducted in the pre-Civil War United States. Imagine the study questions include:

- We should always elevate the interests of white humans over the interests of black humans.

- When white human interests conflict with black human interests, white human interests should be given priority.

- Black humans shouldn't be granted the same rights as white humans with comparable mental capacities.

Imagine that participants in the study answered these questions by rating them on a scale ranging from 1 (= Strongly disagree) to 6 (= Strongly agree). Now suppose that slave owners given a vignette containing moral reasons to avoid slave ownership tended to answer these questions with a rating of 5 and slave owners given a vignette containing only non-moral reasons to avoid slave ownership tended to answer these questions with a rating of 4 . Finally, suppose non-slave owners tended to answer with a rating of 2 . This suggests:

1. The hypothesis that racist belief is caused by cognitive dissonance would not be supported by the hypothetical pre-Civil War study.

2. If (1), then the hypothesis that speciesist belief is caused by cognitive dissonance is not supported by the studies conducted by Jaquet and Cova.

3. So, the hypothesis that speciesist belief is caused by cognitive dissonance is not supported by the studies conducted by Jaquet and Cova.

Regarding premise (1), consider the following hypotheses:

1. H1: Slave-owning causes cognitive dissonance which enhances racist belief.

2. H2: Slave-owning causes cognitive dissonance which is the primary cause of racist belief.

The hypothetical study would support H1. But it would not support H2. It seems to me that any answer to these questions other than "I completely and utterly reject this statement" is racist. If a non-slave owner picks 2 and answers "rather disagree" instead of "strongly disagree", then that suggests to me that the non-slave owner is racist. It suggests that although they wouldn't go all the way and say that we should always elevate the interests of white humans over those of black humans, we should often or at least sometimes do so. That is a racist belief. Even picking 1 and indicating that one "strongly disagrees" with the relevant claim is compatible with thinking there is some truth to the claim

cause, speciesist beliefs predicts that we would have speciesist attitudes towards dogs but even more speciesist attitudes toward the animals we eat. 
and is therefore compatible with racism. The results of the study support H1. But they do not support H2. Rather, they suggest that although slave-owning enhances racist belief, it occurs in non-slave owners and so therefore has an independent cause.

Regarding premise (2): If we started with the hypothesis that racism is primarily caused by cognitive dissonance in slave-owning and then found out that abolitionists reported only some disagreement and not complete disagreement with the racist statements, we would be very surprised. We would think that abolitionists are still pretty racist. The difference between the abolitionist ratings and the slave-owner ratings is the difference between picking the option just under 3 and vacillating between picking 3 and the option just over 3. That difference is not that significant. And we would think that some other factor, besides cognitive dissonance due to slave-owning is needed to explain why we are racists since even the abolitionists are somewhat racist. Similarly, if we started with the belief that speciesism is primarily caused by cognitive dissonance due to meat-eating and then found out that vegetarians reported merely some disagreement and not complete disagreement with the speciesist claims, we would be very surprised. We would think vegetarians are still pretty speciesist. The difference between vegetarian and meat-eater ratings of agreement with speciesist beliefs is a difference between 2 to 3 and 3 to 4. That doesn't seem all that significant. Cognitive dissonance clearly explains how we move from the latter range of scores to the former. But it doesn't yet explain, or at the very least, it isn't required to explain why we start with a level of speciesism at the 2 to 3 range. And whatever the cause of speciesist beliefs, it can't just be cognitive dissonance from meat-eating. There has to be some other source as well.

First Objection: It is a well-known phenomenon in experimental psychology that participants rarely give answers in the extremes ( 1 or 6 ). So it is not surprising that vegetarian participants' mean answer was 2 rather than 1 , even assuming that their cognitive dissonance is extremely low. In these conditions, there is no need to attribute speciesist beliefs in order to account for the data.

Reply: If this is correct, then the experiment is not sufficiently fine grained to distinguish between the hypothesis that vegetarians are less speciesist than meat eaters but still speciesest and the hypothesis that vegetarians are not speciesest at all. For whatever the vegetarians' views about the comparative value of humans and other animals are, they are unlikely to pick 1. If they pick 
in the 3 to 4 range they will approximate the answers of meat eaters. Picking around 2 they indicate that they are less speciesest than meat eaters. But they do not indicate whether they are not speciesest at all. Further experiments are needed to test between the relevant hypotheses. This is consistent with the claim that our hypothesis fits the data at least as well as Jaquet's.

Second Objection: Vegetarians too have interests that conflict with those of animals-especially if they keep consuming eggs and dairy. So, one might expect them to exhibit some amount of dissonance too, which would in turn have some effect on their speciesism scores.

Reply: That is possible. It is also possible that vegetarians feel proud of themselves for doing much more to treat animals better than most humans. And the contrast between their behavior and the behavior of humans who treat them even worse is sufficient to relieve the relevant cognitive dissonance. It is possible that vegetarians enjoy bravely facing up to their wrongdoing and so they embrace the fact that they treat animals less well than they should be treated. It is also possible that because vegetarians have put in effort towards the cause of animal welfare, that their investment causes them to exaggerate the extent to which non-human animals matter so that they can feel more secure in their dedication to the cause. Any of these processes might be at work in addition to cognitive dissonance. Further experimental work is needed.

Third Objection: It would indeed be better for respondents in the racism example to say I completely and utterly reject this statement. This would be evidence that they have very strong antiracist beliefs. And that is the appropriate attitude. Yet, when someone says I strongly disagree with $P$, this cannot be evidence that they believe that P. It is evidence that they disbelieve P. Between antiracist beliefs and racist beliefs, there is suspension of judgment, which our hypothetical participants would have expressed had they answered 3. Only numbers greater than 3 express racist beliefs. Picking 2 indicates antiracist beliefs.

Reply: Distinguish between disagreeing with $\mathrm{P}$ and disagreeing with propositions nearby P. Consider the proposition that all swans are black. Contrast it with other propositions such as some swans are black and a few swans are black. If a participant was asked to indicate agreement with all swans are black on a scale from 1 to 6 and they pick 2, we would conclude that they believe the relevant proposition is false. But we would not conclude that they think some swans are black and a few swans are black is false. Similarly, if a participant is asked to indicate agreement with We should always elevate the interests of humans over the interests of animals on a scale between 1 and 6 and they pick 2 indicating strong disagreement, we would think that they believe the relevant proposition is false. But we would not conclude that they think We 
should sometimes elevate the interests of humans over the interests of animals is false. And agreement with that nearby proposition is sufficient for humans to be speciesest.

Fourth Objection: Jaquet's hypothesis (H1 above) is simpler than ours. He posits only cognitive dissonance (forthcoming, 9). That is sufficient to explain the data. We also posit cognitive dissonance. But we posit another factor as well. A simpler hypothesis is to be preferred over a more complicated one. So Jaquet's hypothesis is to be preferred over ours.

Reply: We do not see how Jaquet's hypothesis is simpler than ours. Both hypotheses posit many psychological processes. There is cognitive dissonance. And there are all the other cognitive process that produce judgments about what matters. On our view, at least one of the later processes causes us to believe humans matter more than other animals. And then that belief is enhanced and distorted by cognitive dissonance. On Jaquet's hypothesis, the later processes would cause us to believe that humans do not matter more than other animals but those processes are overturned by cognitive dissonance.

Fifth Objection: We suggest that Jaquet's central claim is:

H2: Cognitive dissonance in meat-eaters is the primary cause of speciesist belief.

But there is another way to read Jaquet (forthcoming). Perhaps he is instead suggesting that cognitive dissonance has enough of an influence on speciest belief that it makes it an off track process. In that case, Jaquet's debunking argument would still receive support from the relevant studies.

Reply: Virtually all of our beliefs are subject to some degree of influence from off-track processes. But we are arguing, and the objector is granting, that there is a significant amount of speciesism in the absence of meat-eating. So, there is another process at work that has enough influence on its own to produce the beliefs independently of cognitive dissonance. To secure a debunking argument, we need to know whether that other process is off track in order to support the broad conclusion that speciesism is an off track belief. But the relevant studies do not provide any evidence for the claim that that other process is off track.

\section{Acknowledgements}

For comments and discussion, we thank Nathan Nobis, Benjamin Rancourt, and especially Francois Jaquet. 


\section{Reference}

Jaquet, F. (forthcoming). A debunking argument against speciesism. Synthese, 1-17. doi:10.1007/s11229-019-02080-5. 